DOI 10.37882/2223-2982.2020.09.30

\title{
РАЗРАБОТКА И ПРИМЕНЕНИЕ СИСТЕМ РЕАКТИВНОЙ АРТИЛЛЕРИИ НА ВОЕННО-МОРСКИХ СУДАХ В ПЕРИОД ВЕЛИКОЙ ОТЕЧЕСТВЕННОЙ ВОЙНЫ
}

\section{DEVELOPMENT AND APPLICATION OF ROCKET ARTILLERY SYSTEMS ON NAVAL VESSELS DURING THE GREAT PATRIOTIC WAR \\ D. Solovyov \\ S. Sitnikov \\ D. Shchulipenko}

Summary: At the beginning of the great Patriotic war, the Soviet Navy adopted jet weapons, which were placed on the decks of boats and ships in the form of rocket launchers. Its combat use in the Navy installations received in the midst of the fierce battle of Stalingrad and subsequent battles of the war.

The article discusses the features of creating and using rocket artillery systems on ships of the Navy during the great Patriotic war. It shows the decisive contribution to the development of jet installations of the sailor and inventor G.V. Ternovsky, as well as Soviet designers under the guidance of designer V.P. Barmin from the special design Bureau of the Compressor plant in Moscow. The process of manufacturing and testing prototypes of jet artillery in the fleet, their adaptation to sea conditions is covered in detail.

As a result of the success achieved, in June 1942, jet installations were adopted for naval vessels. The result of experimental development of above-deck rocket launchers was their successful use by armored boats, on 0ctober 15, 1942, against ground targets, during the repulse of an enemy attack near the village of Latoshkin. The authors present the main tactical and technical characteristics of marine rocket installations and projectiles. Jet artillery strikes from boats and ships made it possible to achieve success in military and amphibious operations during the war.

Keywords: rocket launchers, rocket projectiles (RS), people's Commissariat of mortar weapons of the USSR, naval Artillery Department.

\author{
Соловьев Дмитрий Николаевич \\ д.и.н., дочент, Санкт-Петербургская \\ юридическая академия \\ botanik-s@yandex.ru \\ Ситников Сергей Павлович \\ преподаватель, Михайловская военная \\ артиллерийская академия \\ odecca74@mail.ru \\ щулипенко Дмитрий Леонидович \\ К.т.н., преподаватель, Михайловская военная \\ артиллерийская академия
}

Аннотация: С началом Великой Отечественной войны на вооружение кораблей Военно-морского флота СССР было принято реактивное оружие, которое в виде реактивных установок разместили на палубах катеров и кораблей. Свое боевое применение на флоте установки получили в разгар ожесточенной Сталинградской битвы и последующих сражениях времен войны.

В статье рассматриваются особенности создания и использования систем реактивной артиллерии на кораблях военно-морского флота в период Великой Отечественной войны. Показан решающий вклад в разработку реактивных установок моряка и изобретателя Г.В. Терновского, а также советских конструкторов под руководством конструктора В.П. Бармина из специального конструкторского бюро завода “Компрессор" в Москве. Подробно освещается процесс изготовления и испытаний опытных образцов реактивной артиллерии на флоте, их адаптация к морским условиям.

Следствием достигнутых успехов стало принятие в июне 1942 г. реактивных установок на вооружение военно-морских судов. Итогом экспериментальных разработок надпалубных реактивных установок было их успешное применение бронекатерами, 15 октября 1942 г., по наземным целям, во время отражения вражеской атаки у поселка Латошкина. Авторами приводятся основные тактико-технические характеристики морских реактивных установок и реактивных снарядов. Удары реактивной артиллерии, наносимые с катеров и кораблей, позволили добиться успеха в ходе военных и десантных операциях в годы войны.

Ключевые слова: реактивные пусковые установки, реактивные снаряды (РС), Наркомат минометного вооружения СССР, Артиллерийское управление ВМФ.
$\Pi^{2}$ редметом статьи является попытка обобщения исторических фактов использования и модификации элементов и составляющих установок, гвардейских минометов, боевых машин реактивной артиллерии, их реактивных снарядов, реактивных систем залпового огня, первоначально разработанных для сухопутных войск, для морских и береговых систем с многоствольными установками, разработанными в период с 40-х годов XX века до наших дней в мире.

Применение реактивных установок, установленных на палубах катеров и кораблей различного класса, имеет глубокую историю. В статье рассматривается только малая часть истории о системах ракетного вооружения военно-морских флотов мира - использование элементов и составляющих гвардейских минометов, реактивных снарядов, реактивных систем залпового огня, первоначально разработанных в мире в интересах сухопутных войск, как для морских реактивных установок, так и береговых реактивных артиллерийских установок в период с 40-х годов XX века до настоящего времени. 
С началом войны флот вернулся к идее использования реактивного оружия. Осенью 1941 г. В Финском заливе на одном из катеров типа Д-3 была успешно испытана пусковая установка для реактивных снарядов РС-30. На Черноморском флоте пусковые установки на четыре снаряда PC-30 каждая были смонтированы на трех торпедных катерах. Катера успешно участвовали в боевых действиях и показали высокую эффективность. Стала очевидным, что применение реактивного оружия на катерах и кораблях флота усилит их атакующие возможности, особенно при нанесении ударов по противнику при высадке десантов, при содействии приморским флангом армий и при боевых действиях на реках. Работ по оснащению катеров и некоторых кораблей флота реактивным оружием шли нарастающими темпами.

Стоит отметить, что «идея создания корабля-ракетоносиа для огневой поддержки десанта зародилась у Георгия Владимировича Терновского во время учебы». В училище, свою дипломную работу он посвятил разработке проекта легких кораблей, имевших в качестве вооружения реактивные снаряды. Проект был оригинальным и обратил внимание, в результате чего лейтенант Терновский после окончания училища получил назначение в одно из центральных управлений, где летом 1939 года «разработал эскизный проект установки реактивного оружия на торпедных катерах и специальных десантных судах». Но практические шаги были сделаны только во время Великой Отечественной войны, в начале 1942 года товарищ Г.В. Терновский сконструировал авиационную реактивную установку для ракет калибра 82 мм. 2 апреля был произведен первый залп по врагу.[1].

Адмирал И.С. Исаев заинтересовался идеей капитана 1 ранга Г.Н. Холостякова после положительного доклада о пройденных испытаниях, на основании этого распорядился установить реактивные установки на торпедных катерах.

Чтобы повысить огневое поражение противника за счёт применения реактивных установок, начальник штаба флота контр-адмирал И.Д. Елисеев одобрил идею применения реактивных установок на торпедных и реактивных катерах. В короткие сроки, по чертежам инженера-механика Н.И. Ясуловича, на ремонтной базе НКВД была сконструирована установка, способная производить пуски до восьми снарядов.

В связи с тем, что реактивные снаряды не справились с морскими испытаниями, было принято решение укладывать по четыре снаряда.

Результаты эффективного применения ракетных установок способствовали дальнейшему совершенствованию и модернизации.
Адмирал Галлер в своих записях говорил о необходимости применения реактивных установок на кораблях Военно-морского и речного флота. [2].

В период с февраля 1942 года по май 1942 года была разработана пусковая установка М-8-М башенно-палубного типа для стрельбы неуправляемыми реактивными снарядами М-8 калибра 82 мм использованных для стрельбы с сухопутных установок М-8-36 и железнодорожных установок. Она предназначалась для обеспечения выполнения боевых задач по поражению массированным огнем незащищенных береговых и морских целей, а также защиты катера или корабля от низколетящих самолетов противника. В состав метательной установки входил пакет из 12 направляющих типа "балка" длиной 2000 мм каждая. Направляющие крепились на каркасной ферме, собранной из трубчатых заготовок [3].

Ведущим конструктором был Александр Николаевич Васильев. В мае 1942 года на московском заводе "Компрессор" были изготовлены опытные образцы, которые успешно прошли испытания и были рекомендованы к принятию на вооружение Военно-Морского Флота. В августе 1942 года была изготовлена первая партия в количестве десяти боевых установок М-8-М для вооружения Волжской и других флотилий. Установки были применены в переломной для Великой Отечественной войны Сталинградской битве [4].

Также, весной 1942 года, Наркомат минометного вооружения дает указание разработать и провести совершенствование реактивных установок с учётом предыдущих недостатков, выявленных в ходе испытаний. При проведении оборонительных операций стрельба неуправляемыми снарядами калибра 132 и 82 мм обеспечивала поражение живой силы и техники противника. Конструктивно использовались установки, которые ранее применялись на различных флотилиях и флотах.

Первый образец, изготовленный на заводе «Компрессор», проходил испытания на Волжской военной флотилии, результатом которых стал акт, утвержденный Народным комиссариатом Военно-морского флота. В ходе успешно пройденных испытаний было принято решение о выпуске партии из 20 установок.

В первой половине 1942 года Наркомат минометного вооружения СССР дает указание разработать боевую 32-зарядную реактивную установку для проведения пуска реактивных снарядов калибра 132 мм. Конструктивная переработка всей метательной установки помогла увеличить количество снарядов в залпе, тем самым, обеспечивая большую огневую мощь.

Разработанная по указу Наркомата минометного вооружения, 16-зарядная установка предназначалась для 
тех же целей, что и прошлые модели.

Установка была принята для вооружения кораблей Военно-морского флота и применялась в Сталинградской битве, а также в других боевых операциях. [5].

В июне-июле 1942 года по заданию Наркомата и исходным данным, полученным из Артиллерийского Управления ВМФ, был разработан новый вариант боевой 24-зарядной установки М-8-М. Ранее разработанная боевая установка М-8-М, смонтированная на броневом катере предусматривала использование минимально доработанной метательной установки боевой установки М-8 на доработанном шасси грузового автомобиля 3ИС6. В новой установке М-8-М вся метательная установка, кроме направляющей, унифицированной с направляющей установки М-8 на доработанном шасси танка Т-40 (Т60), была разработана заново, с учетом специфичности условий ее работы и обслуживания в морских условиях [6].

Назначение новой установки было то же, что и для установки М-8-М. Конструкция нового варианта установки М-8-М была выполнена однотипной по сравнению с боевой установкой М-13-М, смонтированной на бронекатере. Новый проект был утвержден в Артиллерийском Управлении ВМФ.

Учитывая специфические корабельные условия, советские конструкторы специального конструкторского бюро московского завода "Компрессор" под руководством главного конструктора В.П. Бармина во второй половине мая 1942 года разработали ряд морских экспериментальных пусковых установок, изготовление и испытание которых завершилось в конце мая того же года. Установка 24-М-8 (24 реактивных снаряда) относилась к башенно-палубному типу и состояла из качающейся части, основания, прицельного устройства, механизмов наведения и электрооборудования. Диапазон углов возвышения, скрепленной с основанием качающейся части составлял от 5 до $45^{\circ}$, а поворотная часть перемещалась в горизонтальной плоскости на $360^{\circ}$. Внутри поворотной части монтировались механизмы вертикального и горизонтального наведения, прицельное устройство и электрооборудование.

Интервал между выстрелами составлял 0,3 с, а все 24 снаряда сходили с направляющих за 16 оборотов (7-8 с.) переключателя прибора управления огнем [7].

Установка 16-М-13 (16 снарядов) - надпалубного типа: могла крепиться на крыше боевой рубки бронекатера (по предложению из СКБ) или устанавливалась вместо кормовой башни танка Т-34. Она наводилась на цель и заряжалась с надпалубной части пусковой установки. За один оборот маховика переключателя производился один выстрел, все 16 снарядов сходили с направляющих за 5-8 с. В мае 1942 г. опытные образцы установок 24-М8 и 16-М-13, изготовленные на заводе, были поставлены на бронекатера № 350 и 314, входившие в состав Волжской военной флотилии. Испытания прошли успешно. 15 октября 1942 г. бронекатера-ракетоносцы № 41 и 51 получили задание поддержать огнем реактивных снарядов 138-ю стрелковую дивизию, отражавшую вражеские атаки у северной окраины поселка Латошинка. Впервые в истории советского ВМФ наземные цели поражались совместной залповой стрельбой реактивными снарядами М-13 с палуб бронекатеров.

До окончания Великой Отечественной войны было изготовлено 35 единиц установок 16-М-13 [8].

В ходе изучения архивных данных Центрального Военно-Морского Архива соавтором Гуровым С.В. были установлены следующие данные о начальном этапе работ по установкам М-8-М и М-13-М.

Артиллерийским Управлением Военно-морского флота были изготовлены первые образцы реактивных установок, а позже, с заводом «Компрессор» состоялось заключение договора на совместную разработку и изготовление реактивных установок.

В июне 1942 года изготовленные по одной опытной установки М-8-М и М-13-М были установлены на бронекатерах типа 1125 и 1124, и были испытаны комиссией на Волжской Военной Флотилии (ВВФ) (приказы НКВМФ №00143 и 00170 от 1942 года).

На основании результатов испытаний в июне, реактивные установки были приняты на вооружение катеров и некоторых кораблей.

Две испытанные опытные установки вступили в строй кораблей Волжской Военной Флотилии в июне 1942 года.

По ходатайству ВМФ в августе 1942 года, на основании Постановления Совнаркома №14724рс от 6 августа 1942 года, на заводе № 733 НКМВ для ВМФ было предусмотрено изготовление 30 установок М-8-М и 20 установок М-13-М.

Одновременно заместитель председателя СНК Союза ССР т.Берия был распоряжение ГУВГМФ Ст.Верх.Главн. Командования по обеспечению изготовленных установок в ВМФ боезапасом.

В августе 1942 года на Волжской Военной Флотилии была испытана вторая опытная установка М-13-М, изготовленная заводом № 733, с учетом конструктивных доделок и изменений отмеченных комиссией и смонтиро- 
ванная зав.№340 (г.Зеленодольск) на бронекатера типа 1124. Испытания показали положительные результаты, и бронекатер с установкой М-13-М вошел в строй ВВФ.

В сентябре 1942 года в строй кораблей ВМФ вошли еще четыре бронекатера, вооруженных опытными установками М-8-M.

Отработка конструкции, монтаж и испытания опытных установок проводились представителями АУ и УК совместно.

Вопросы боевого использования, обучение команд, обеспечение боезапасом, таблицами стрельбы, инструментами и директивными указаниями флотам по использованию Р.С. проводились АУ ВМФ.

В ноябре 1942 года решением НКВМФ **118сc - 30 октября 1942 года все вопросы производства реактивных установок и вооружения ими кораблей ВМФ, снабжения реактивным боезапасом были переданы АУ ВМФ.

29 ноября 1942 года реактивные установки М-8-М и М-13-М принимают на вооружение кораблей приказом Народного комиссариата Военно-морского флота.

Кроме изготовления на заводе №733 штатных реактивных установок М-8-М и М-13-М и установки их на кораблях ВМФ, Артиллерийское Управление в 1942 году давало руководящие указания по применению реактивных установок, изготавливавшихся самостоятельно на Северном Флоте, Краснознамённом Балтийском Флоте и Черноморском Флоте.

В течение августа-декабря 1942 года было изготовлено следующее количество установок: 31 установка M-8-М, из которых 11 опытных и 20 серийных, а также 2 опытные установки М-13-М.

Установки были установлены:

- 1 шт. М-8-М (опытн.) на катере БК-1125;

- 4 шт. М-8-М (опытн.) на катерах ТК типа Я-5;

- 6 шт. М-8-М (опытн.) на катерах ТК типа Г-5;

- 2 шт. М-8-М (серийн.) на катерах ТК типа Г-5;

- 6 шт. М-8-М (серийн.) на катерах ТК типа Я-5;

- 2 шт. М-13-М (опытн.) на катерах типа БК-1124;

- 10 шт. М-8-М (серийн.) отправлены на зав.№340 для установки на катерах типа БК-1125 и типа TK$\Gamma-5$;

- 1 шт. М-8-М (серийн.) отправлена на зав.№344 для установки на катере типа ТК Г-5;

- 1 шт. М-8-М (серийн.) отправлена на Краснознаменный Балтийский Флот [9].

Конструктивные недостатки, выявленные входе эксплуатации установок М-8-М и М-13-М, предназначенных для применения при стрельбе с якоря, понижающие боевую эффективность. следующие:

- штифты снарядов отрывались при переходе морем из-за ненадежного крепления;

- недостаточная прочность установки М-8-М в целом в условиях качки и вибрации катера;

- малые скорости вертикального и горизонтального наведения и большие усилия на штурвалах, затруднявшие беспрерывное слежение за целью на качке катера;

- негерметичность установки и прицельных приспособлений от попадания морской воды и пороховых газов;

- конструкция пиропистолетов не обеспечивала герметизацию пиропатронов, которые увлажнялись(отсыревали) и давали отказы /установка М-8-M/;

- неудовлетворительность прицельных приспособлений;

Во второй половине 1942 года были проведены испытания, во главе которых был ведущий конструктор завода «Компрессор» В. Бармин

Применение 24-зарядной реактивной установки позволило выполнять задачи в секторе до $360^{\circ}$ и с повышенным углом возвышения.

Уникальность 16-зарядной реактивной установки заключалась в том, что она могла крепиться как на бронекатерах, так и на других морских судах.

Темп стрельбы из пусковых установок позволял выпустить весь боекомплект (24 снаряда 82-мм калибра и 16 снарядов 132-мм калибра) за 7-8 с.

29 ноября 1942 г. Приказом наркома ВМФ установки 24-М-8 и 16-м-13 были приняты на вооружение кораблей. Отечественная промышленность в широких масштабах наладила выпуск реактивных снарядов РС-30 132-мм калибра и РС-82 82-мм калибра. Пусковые установки для них монтировали сначала на переоборудованных для этих целей кораблях, а затем и на серийных бронекатерах в ходе их постройки.

Для пополнения кораблей Волжской военной флотилии, например, были переоборудованы торпедные катера, с них снимали торпедные аппараты и устанавливались 82-мм 24 зарядные системы 24-м-16 («Катюши»). Волжская военная флотилия получила и серийные бронекатера, вооруженные реактивными снарядами. Пусковые установки 16-м-13 (на 16 снарядов РС-30) и 24-м-8 (на 24 снаряда PC-82) были размешены на бронекатерах вместо башенных ракетных установок.

В процессе производства реактивных установок во 
Таблица 1

\begin{tabular}{|l|c|c|c|c|c|} 
& M-8-М & М-13-М & $\begin{array}{c}\text { Конструкции Красно3- } \\
\text { намённого Балтийского } \\
\text { флота (К.Б.Ф.) }\end{array}$ & $\begin{array}{c}\text { Конструкции Черно- } \\
\text { морского флота (Ч.Ф.) }\end{array}$ & $\begin{array}{c}\text { Конструкции Северного } \\
\text { флота (С.Ф.) }\end{array}$ \\
\hline С.Ф. & - & - & - & - & $4 / 4$ \\
\hline К.Б.Ф. & $1 / 24$ & - & $24 / 6$ & - & - \\
\hline Ч.Ф. & $1 / 24$ & - & $10 / 6$ & $10 / 4$ & - \\
\hline ВВФ (Волжская Военная Флотилия) & $19 / 24$ & $2 / 16$ & - & - & - \\
\hline
\end{tabular}

Примечание: В числителе указано число установок, а в знаменателе - число направляющих в составе каждой установки[12,C.42; С.34 (расшифровка ВВФ)].

Таблица 2

\begin{tabular}{l|l|c|c|c|c|}
\hline \multirow{2}{*}{$\begin{array}{l}\text { № } \\
\text { п.п. }\end{array}$} & Наименование установки & Количество, подлежащее & \multicolumn{3}{|c|}{ Данные по месяцам } \\
\cline { 3 - 6 } & & поставке в І квартале & январь & февраль & март \\
\hline 1 & Реактивных установок М-8-М & 35 шт & 10 & 10 & 15 \\
\hline 2 & Модернизированных реактивных установок М-8-M & 10 шт & - & - & 10 \\
\hline 3 & Реактивных установок М-13-М & 20 шт & 10 & 10 & - \\
\hline 4 & Опытная реактивная установка двухрядка М-8-М & 1 шт & - & - & 1 \\
\hline
\end{tabular}

второй половине 1943 года, часть перечисленных недостатков была устранена. Среди них:

- достигнута герметизация установок и прицельных приспособлений;

- введен сепаратор, значительно улучшающий горизонтальное наведение;

- на Черноморском Флоте пиропистолеты были переделаны под трубку ГТК-П и был устранен ряд менее существенных недостатков $[10,11]$.

Далее приведем данные о наличии реактивных установок флотах и флотилиях (документ от 16 февраля 1943 года).

В копии документа выписка из ведомости поставки реактивных установок в первом квартале 1943 года по договору №8/95072с, заключенному Артиллерийским Управлением Военно-Морского Флота (АУ ВМФ) с заводом №733 Народного Комиссариата Миномётного Вооружения (НКМВ) указаны следующие данные [13, С.31].

Далее приведем несколько фактов о применении установок для пуска реактивных снарядов.

В журнале боевых действий бронекатера №14 29 августа 1942 года была сделана следующая запись: «29.08.42 г. Вели огонь по д. Рынок из М-8. Израсходовано 45 реактивных снарядов. Уничтожен взвод автоматчиков» [14].

1 августа 1942 года торпедные катера «Д-3» (ст. лейтенант О.М. Чепик) и «СМ-3» (лейтенант М.К. Гурин) под общим командованием ст.лейтенанта К.Г. Кочиева совер- шили набег на б.Двуякорная. На рассвете катера вышли к цели. Десантная баржа противника была обнаружена в бухте. С катеров были запущены торпеды, а затем обстреляли противника реактивными снарядами и пулемётным огнём. Для противника нападение оказалось совершенно неожиданным. Ответный огонь был открыт с запозданием. Обстрел привёл к потере противником десантной баржи F-334. Прикрывшись дымовыми завесами, катера ушли в свою базу без потерь (ЦВМА. Ф. 173. Д. 5071. Л. 8,9) [17].

В журнале боевых действий бронекатера №51 31 августа 1942 года было записано следующее: «31.08.42 г. Дано два залпа реактивными снарядами М-13. Уничтожено два дзота и четыре пулеметных гнезда»[14].

Во время обороны Севастополя в ночь на 27 декабря 1942 года катер МО СКА №014 и катер СКА № 074, вооруженные двумя реактивными установкми М-8 каждый выполнели огневой налёт на артиллерийскую батарею противника у хутора Алексин в районе м.Мысхако. С катеров были запущены 40 реактивных снарядов, чем было обеспечено подавление батареи [15].

Делая вывод, следует отметить, что применение данных систем вооружения на кораблях оказало на противника сильное психологическое воздействие. Реактивные удары, наносимые с катеров и кораблей помогли добиться больших успехов на военных и десантных операциях в Великой Отечественной войне

Инициатором и энтузиастом идеи стал капитан-лейтенант Г.В. Терновский, разработчиком технологий про- 
Основные тактико-технические данные морских реактивных установок

\begin{tabular}{|c|c|c|c|c|c|}
\hline \multicolumn{6}{|c|}{ Основные тактико-технические данные морских реактивных установок [16, С.109-110] } \\
\hline \multirow[t]{2}{*}{ Наименование данных } & \multirow[t]{2}{*}{ Ед. изм. } & \multicolumn{4}{|c|}{ Наименование установок } \\
\hline & & M-8-M & 24-M-8 & M-13-M & $16-\mathrm{M}-13$ \\
\hline Калибр & MM & 82 & 82 & 132 & 132 \\
\hline Число направляющих & $u m$ & 24 & 24 & 16 & 16 \\
\hline Длина направляющих & MM & 2000 & 2000 & 5000 & 4000 \\
\hline Наибольшая дальность & M & 5515 & 5515 & 8470 & 8470 \\
\hline Продолжительность залпа & $c$ & $5-6$ & $2-3$ & $5-6$ & $2-3$ \\
\hline \multicolumn{6}{|l|}{ Вертикальное наведение: } \\
\hline а) угол возвышения & град & 45 & 55 & 45 & 60 \\
\hline б) угол снижения & $"$ & 0 & $5^{*}$ & 0 & $5^{*}$ \\
\hline в) скорость наведения (заряженной установки) & град/c & 0,85 & 12 & 0,33 & 7 \\
\hline г) усилие на штурвале (заряженной установки) & K2 & $8-10$ & $3-4$ & 12 & $3-4$ \\
\hline \multicolumn{6}{|l|}{ Горизонтальное наведение } \\
\hline а) угол обстрела & град & 360 & 360 & 360 & 360 \\
\hline б) скорость наведения & гpad/c & 8,5 & 12 & 3,5 & 6 \\
\hline в) усилие на штурвале & K2 & $6-7$ & $3-4$ & $15-16$ & $5-6$ \\
\hline Прицельные устройства & - & $\begin{array}{l}\text { KM-1 } \\
\text { ПТМ }\end{array}$ & ПТМ-1 & $\begin{array}{c}\text { KM-1 } \\
\text { ПТК } \\
\end{array}$ & $\begin{array}{c}\text { ПТМ-1 } \\
\text { ПТК }\end{array}$ \\
\hline Диаметр по шарам & MM & 1341 & 950 & 1802 & 1525 \\
\hline \multicolumn{6}{|l|}{ Габаритные данные: } \\
\hline а) длина & MM & 2195 & $2242(2240 * *)$ & 5060 & 4000 \\
\hline б) ширина & $"$ & 2150 & $2427\left(2430^{* *}\right)$ & 2235 & 2550 \\
\hline в) высота & $"$ & 1025 & $1166\left(1170^{* *}\right)$ & 2140 & 2015 \\
\hline Радиус обметания & $"$ & 1600 & 1835 & 3500 & 3175 \\
\hline \multicolumn{6}{|l|}{ Весовые данные: } \\
\hline а) вес незаряженной установки & K2 & 800 & 975 & 2100 & 2100 \\
\hline б) вес заряженной установки & $"$ & 992 & 1167 & 2780 & 2780 \\
\hline в) вес снаряда & $"$ & 8 & 8 & 42,5 & 42,5 \\
\hline Время перезаряжания & мин. & $4-8$ & $4-8$ & $4-8$ & $4-8$ \\
\hline \multicolumn{6}{|l|}{ Боевой расчет: } \\
\hline а) при стрельбе & чел. & 1 & 1 & 2 & 2 \\
\hline б) при перезаряжании & $"$ & $2-3$ & $2-3$ & $3-4$ & $3-4$ \\
\hline
\end{tabular}

Весовые данные установок М-13-М и 16-М-13 в источнике [16, С.110] зачеркнуты карандашом. Кто выполнил зачеркивание в источнике не указывается.

*имеется в виду -5 (минус пять).

** даны габаритные данные надпалубной части [16]

изводства ведущий конструктор московского завода «Компрессор» А.Н. Васильев.

В завершении статьи о работах в годы Великой Отечественной войны приведем основные тактико-технические данные морских реактивных установок и реак- тивных снарядов.

1. Данные по 82-мм снаряду М-8 балистического индекса ТС-11 даны для снаряда с нормальным корпусом и удлиненной головкой, укомплектованного взрывателем ГВМЗ.

2. Снаряды М-13 с балистическим индексом ТС-29 
отличаются от снарядов М-13 с балистическим индексом ТС-13 только наличием дополнительно переходного дна, посредством которого соединяются цилиндрическая и головная части снаряда $[16$, C.111].

3. Снаряды М-8 балистического индекса ТС-12 с вооружения были сняты, и стрельба ими воспрещалась $[16$, С.62].
4. Снаряды М-13 с балистическим индексом ТС-14 с вооружения были сняты, и стрельба ими воспрещалась [16, С.65].

После окончания Великой Отечественной войны работы по морским установкам с использованием элементов и составляющих сухопутных систем реактивной артиллерии были продолжены.

\section{ЛИТЕРАТУРА}

1. Новиков М. Залпы «Скумбрии». Память огненных лет // Красная звезда. - №55(17442) - 07 марта 1981 г. - С. 4.

2. ЦЦентальный Архив Министерства Обороны Российской Федерации (далее ЦАМО РФ) (Россия, г.Подольск). Ф. 59. Оп. 12200. Д. 125. Л. 63.

3. К Каткая история СКБ-ГСКБ Спецмаш-КБОМ. 1 книга. Создание ракетного вооружения тактического назначения 1941-1956 гг. - М.: Конструкторское бюро общего машиностроения, 1967. - С. 32.

4. Первицкий Ю.Д., Слесаревский Н.И. Первые ракетно-пусковые установки на малых боевых кораблях Черноморского флота (Рабочие материалы неизданной книги - электронный вариант).

5. Краткая история СКБ-ГСКБ Спецмаш-КБОМ. 1 книга. Создание ракетного вооружения тактического назначения 1941-1956 гг. - М.: Конструкторское бюро общего машиностроения, 1967. - С. 32-33.

6. Краткая история СКБ-ГСКБ Спецмаш-КБОМ. 1 книга. Создание ракетного вооружения тактического назначения 1941-1956 гг. - М.: Конструкторское бюро общего машиностроения, 1967. - С. 33.

7. Первицкий Ю.Д., Слесаревский Н.И. Первые ракетно-пусковые установки на малых боевых кораблях Черноморского флота (Рабочие материалы неизданной книги - электронный вариант).

8. Васильев А. Рождение корабельных «катюш» // Морской сборник. - № 11. - 1980. - С. 69.

9. Ц Центральный Военно-Морской Архив (далее ЦВМА) (Россия, г.Гатчина). Ф. 430. Оп. 1. Д. 1282. Л. 91,92. Неподписанный Отчет о работе 8-го отдела АУ ВМФ за 1942 год.

10. ЦВМА. Ф. 430. Оп. 1. Д. 1282. Л. $98,99$.

11. Российский Государственный Архив Социально-Политической Истории (далее РГАСПИ) (Россия, г.Москва). Ф. 644. Оп. 1. Д. 156. Л. 76. Распоряжение № ГОКО-4252сс“0 плане производства и ремонта боевых установок М-13 и М-8 в IV квартале 1943 года" от 5 октября 1943 г.

12. РГАСПИ. Ф.644. ОП. 1. Д. 418. Л. 24. Постановление ГОКО № 8651сс“0 плане производства и поставки артиллерийского, минометного, стрелкового вооружения и военных приборов НКО СССР в июне-июле 1945 г" от 17 мая 1945 г.

13. ЦВМА. Ф. 430. 0п. 1.Д. 347.Л. 42.

14. Васильев А. Рождение корабельных «катюш» // Морской сборник. - №11. - 1980. - С.68 (копия статьи с указанием источника).

15. Боевая летопись военно-морского флота 1941-1942. Авторский коллектив. МО СССР. М.: Воениздат, 1983

16. Описание морских реактивных установок и боеприпасов. Артиллерийское Управление Военно-морских сил. Ленинград: Воениздат, 1946

$$
\begin{gathered}
\text { (c) Соловьев Дмитрий Николаевич (botanik-s@yandex.ru), Ситников Сергей Павлович (odecca74@mail.ru), } \\
\text { Щулипенко Дмитрий Леонидович. } \\
\text { Журнал «Современная наука: актуальные проблемы теории и практики» }
\end{gathered}
$$

